\title{
Healthcare related advertising: Misinformation and manipulations
}

\author{
Manish Pokhrel
}

Access to basic healthcare is a fundamental right of every citizen. ${ }^{1}$ Yet, in a country like ours where private institutions cater to the healthcare needs of a disproportionately sizable population, ${ }^{2}$ the business nature of the service cannot be underestimated as well. The need and right to advertise is intricately linked to business. However healthcare delivery is a complex enterprise and labelling healthcare as a mere business and patient as a consumer is morally unsound. Therefore the same standards of advertising cannot be expected to do justice for both healthcare and other consumer businesses.

While there are rules in place for governing advertisements for healthcare service providers, ${ }^{3,4}$ we frequently witness gross violations of such regulations in electronic and print media advertisements. Things get more convoluted when alternative and non-standard medical practices which hold widespread public appeal in our part of the world feature advertisements that make unchallenged and unscientific claims, often because they are poorly regulated and easily pass through the loopholes of the regulating bodies. This gives rise to the same age-old debate as to whether healthcare should involve itself in advertising at all.

The proponents of health advertisement to the general public have traditionally argued in favour of upholding the spirit of free trade. ${ }^{5}$ Others have also argued that physician advertisements help to inform patients about the interests of the physician, lets the patient know about available alternative options and improves the overall physicianpatient relationship. ${ }^{6}$ An important sequelae to this argument is that the same advertisements can employ common advertising techniques to manipulate the understanding of healthcare services. ${ }^{7}$ However, it must be remembered that the fiduciary nature of healthcare services runs deeply contrapuntal to the notion of choice and free-will on the part of the patients. This puts the physician in a position of predicament when health care services are advertised directly to the patient, especially in the background of toxic and manipulative advertising practices.

\section{Toxic advertising practices:}

Advertisements based on defamation of the competition are quite frequently seen among consumer goods. While such advertisements help increase the sale of one product, they also cause loss of sale for the competition. Such types of defamatory advertisements in healthcare carry implications far beyond matters of simple economics.

The portrayal of conventional and standard treatments for cancers as 'toxic' and 'harmful' is a recurring theme among advertisements promoting 'traditional' and 'natural' remedies. It is a known fact that the treatment of cancers, be it surgery or other modalities like chemotherapy and radiotherapy comes with an array of side-effects and potential complications. It is quite understandable for the patient and their relatives to be distressed by such a challenging course of treatment with seemingly no guarantee of cure. These people can be easily swayed to other non-standard forms of treatments that 'guarantee success without side-effects'.

Patient testimonials featuring success of treatment is another commonly employed advertising technique rampantly seen in the advertisements for herbal and naturopathy treatments. Often these advertisements claim to feature 'patients' of kidney diseases or cancers who were advised for a 'costly' and 'hazardous' treatment by doctors, and after a referral by a 'friend' came to know of this alternative 'miracle' treatment based on 'ancient scriptures' and are now 'cured'. These kinds of advertisements prey on the fact that patients often look for justification of an easy and alternate way that they wish in lieu of a more lengthy standard process, and patient testimonials provide them with the validation that they deeply desire. However the average lay person fails to acknowledge that most of the times these are cookedup scenarios and fake patients, and even when real, patient testimonials are always misleading because they always feature success stories, and never mention the failures. It is worth pondering how many times we have witnessed patients who have stopped taking regular anti-hypertensive
Author affiliations:

Department of Paediatric Surgery,

Nobel Hospital Pvt. Ltd., Sinamangal, Kathmandu, Nepal.

\section{Correspondence:}

Dr. Manish Pokhrel,

Assistant Medical Director, Consultant Paediatric Surgeon,

Nobel Hospital Pvt. Ltd., Sinamangal, Kathmandu, Nepal.

E-mail: guru0941@gmail.com

ORCID: https://orcid.org/0000-0001-5216-7628
How to cite this article:

Pokhrel M. Healthcare related advertising: Misinformation and Manipulations. J Soc Surg Nep. 2020 Dec; 23(2):1-3.

\section{Copyright information:}

DOI: https://doi.org/10.3126/jssn.v23i2.35792 
medications or stopped treatment of cancers to try these 'miracle healing methods' and have ended up with dreaded consequences.

Misinformation is another extensively used tool not only in healthcare related advertisements but in all types of advertisements in general. Nepalese radio-stations and television channels constantly feature advertisements of natural healers touting 'no-side-effect' treatment of conditions as diverse as piles and fistula to jaundice and sexual conditions. Also in the same bandwagon are advertisements of 'Chinese therapists' that claim to treat various surgical conditions without operation, along with a promise of free medical check-up. It is standard practice to counsel patients for any procedure by describing not only the benefits and strengths of that procedure but also the possible complications, alternative options and achievable outcomes. Simply touting a treatment as having 'no-side effects' and providing 'guaranteed success' qualifies as misinformation and is downright illegal.

Misinformation in healthcare advertisements have also employed subtle tactics and clever use of statistics like using out of place numbers, percentages without telling the size of population, bias and conflicts in fine print, confusing abbreviations and the use of scientific sounding words. Common words and phrases that appeal to the masses like 'wellness', 'holistic', 'natural', 'traditional', 'cleansing the body' etc. are used loosely and can be interpreted in many different ways when confronted as to their true intent. 'Puffery', using statements that cannot be tested and demonstrated to be factually incorrect, like 'outstanding service', or 'care-par-excellence' is also a constant feature in such advertisements. Although advertisements give an impression of choice among the consumer as to the alternative methods of treatment available to them, it undervalues the fact that such choice has been created by selective promotion of one service based on deception. Since the entire premise is based on misinformation, the consumer's right to informed purchase has been violated.

Use of movie celebrities and sport stars as health ambassadors to promote public health issues like sanitation and vaccinations are not new. However when one uses his status as a popular celebrity or a media person to make judgements on issues that require scientific understanding then this qualifies as an appeal-to-false-authority. In the similar spectrum are actors 'dressed' as doctors who make false and misleading health-related claims. Often the advertising agencies are expecting the lay public to take those statements at face value and not question the integrity of the information because that information has been relayed through a celebrity or a medical professional.

With the access to digital platforms, a new trend of producing educational videos by medical professionals for the public related to various medical conditions has emerged. Although these have academic connotations, sometimes these videos are sponsored by health facilities, health manufacturers and some are blatantly promotional in intent. Whether they qualify as self-advertisement is a debate for another time. While it is considered ethical for clinicians to promote their work, such promotions must be truthful, non-discriminatory and non-misleading. All conflicts of interests and financial backing must be honestly stated so that the consumer can make an informed decision and also weigh in the motive behind such promotions.

\section{Implications for the general public:}

The foremost implication of misinformed advertisements is faced directly by the patients themselves. Because most of the advertisements belong to alternative medical practices, many patients are lured by misinforming advertisements into pursuing non-standard treatment modalities and lose valuable time and resources that they could have allocated to timely and proper treatment of their conditions. In fields such as oncology, this delay could mean converting a favourable outcome in the form of complete remission of cancer to something as dreaded as death. Apart from causing a delay in seeking standard treatment, alternative medical practices have also been reported to cause significant harm to the patients and their claim that 'natural substances cause no side effects' should be taken with a pinch of salt. ${ }^{8-11}$

Another unforeseen aspect is that the relentless playback of misinformation in these kinds of unregulated advertisements fuels the slow erosion of public impression on what comprises standard treatment modalities. Public understanding and opinions can be shaped by subtle advertising techniques, which can lead to demand for useless treatments and expectations of unachievable outcomes. Physicians have to devote considerable time and energy to realign the patient from unrealistic expectations created by such misinforming advertisements.

In an age when self-diagnosis aided by internet knowledge is common we have frequently witnessed patients arrive to healthcare facilities after a failed trial of home or alternative therapies that were advised by supposed 'healers/ naturopaths' advertising in internet sites (also claiming that their treatment is so secret and effective that doctors are trying to hide them). Medical professionals devote considerable time and energy in acquiring the knowledge and skills that they require in their chosen field. They pore over peer-reviewed papers for the latest developments in their field, and are trained to filter new ideas with a scientific scepticism before committing them to practice, while lay people are hammered with advertisements promising miracle outcomes without bothering with the details. One cannot help wonder how prudent it is in these circumstances to expect that the patients will make the best possible decision for themselves when given the choice of available options to them. That is precisely the fabric of trust ingrained in the so called doctor-patient relationship, which is threatened in the era of misinforming advertisements.

These kinds of unregulated advertisements also raise the possibility of conflicts and litigations among the patients 
and the healthcare service providers. Since these types of advertisements create expectations of unachievable outcomes in patients, even a common complication of standard treatment is met with public outrage. If such advertising practice continues, there will come a time in the not-so-distant future when a surgeon who has successfully removed an aggressive cancer is confronted by the patient for not giving him the timely option of the cheaper, nonoperative, natural treatment that could have been achieved with just a few doses of 'jamara-ko-juice'.

\section{References}

1. The Public Health Service Act of 2075 (2018), Government of Nepal. (18 September 2018). Available from: http://www.lawcommission.gov. np/en/wp-content/uploads/2019/07/The-PublicHealth-Service-Act-2075-2018.pdf

2. Department of Health Services. Annual Report 2018/19. Government of Nepal; 2019.iii. Available from: http://dohs.gov.np/wp-content/ uploads/2020/11/DoHS-Annual-ReportFY-075-76-.pdf

3. Advertisement (Regulation) Act of 2019. Nepal Gazette 69. Suppl 15.Part 2. Published 25 Oct 2019. Available from: http://rajpatra.dop.gov.np/ welcome/book/?ref=23847

4. Code of Ethics and Professional Conduct-2017. Nepal Medical Council; 2017. 4 p. Available from: https://nmc.org.np/files/4/Code \%20of\%20Ethics Print_version.pdf

5. Barnes EG. The Federal Trade Commission's American Medical Association Case and Other Health-Related Activities, Food Drug Cosmetic Law Journal. 1982;37:237-43.

\section{Conclusion}

Advertisements that relate to healthcare are replete with misinformation and cause selective shaping of public view against standard medical practices. Such advertisements need to be brought under regulation or stopped for the benefit of the patients.
6. Zwier S. The neglected repercussions of a physician advertising ban. J Med Ethics. 2014;40:198-201.

7. Delmas C. Three reasons to ban advertising for health care services. The American Journal of Bioethics. 2014;14(3):51-2.

8. Grewal P, Ahmad J. Severe liver injury due to herbal and dietary supplements and the role of liver transplantation. World J Gastroenterol. Dec 14 2019;25(46):6704-12.

9. Amadi $\mathrm{CN}$, Orisakwe OE. Herb-induced liver injuries in developing nations: an update. Toxics. 2018 Jun; 6(2):24.

10. Lin NH, Yang HW, Su YJ, Chang CW. Herb induced liver injury after using herbal medicine: a systematic review and case-control study. Medicine (Baltimore). 2019 Mar; 98(13):e14992.

11. Lim A, Cranswick N, South M. Adverse events associated with the use of complementary and alternative medicine in children. Archives of Disease in Childhood. 2011;96(3):297-300. 